Chapter 19

\title{
Approaches to Managing Executive Cognitive Functioning Impairment Following TBI: A Focus on Facilitating Community Participation
}

\author{
Steven Wheeler \\ Additional information is available at the end of the chapter
}

http://dx.doi.org/10.5772/57395

\section{Introduction}

Successful and satisfying community living represents the ultimate outcome of traumatic brain injury (TBI) rehabilitation. Unfortunately, for the vast majority of affected individuals, full participation in pre-injury roles and responsibilities is negatively impacted by a complex mix of cognitive, physical, emotional, psychological, and behavioral impairments. Each individual living with TBI is unique and a reflection of numerous factors including pre-injury characteristics, severity of injury, home and community supports, and related internal and external factors. The TBI literature often depicts life following TBI as unproductive, including the need for varying levels of caregiver assistance and supervision. Long-term recovery following TBI is characterized by reduced independence in home and community activities including employment, parenting, driving, and participation in leisure activities [1]. Additionally, TBI is frequently associated with profound social isolation and decreased life satisfaction.

Problems of community re-entry following TBI carry enormous personal and societal costs. This chapter will focus on rehabilitation approaches for executive cognitive functions, a set of cognitive abilities that control and regulate goal directed behavior. Often considered higher level cognitive abilities, executive functions include the ability to initiate, modify, and stop actions, to monitor behaviors and adjust them to appropriately suit a situation, to plan future behavior when faced with unfamiliar situations, and to anticipate outcomes and adapt to changing situations. They include the self-regulation or self-control functions that enable individuals to understand their strengths and limitations, formulate goals, devise ways to achieve them, and effectively implement the plans. They also influence more basic cognitive abilities such as attention and memory and are essential to adult role participation, involving 
the ability to engage in independent daily activities. One's ability to initiate, plan, set goals, monitor performance, anticipate consequences and respond flexibly and adaptively are all dependent on executive cognitive functions.

Executive functions are commonly impaired following moderate to severe TBI due, at least in part, to damage of the frontal lobes and subcortical limbic system. As "control" functions, executive cognitive functions enable people to engage in controlled behavior beyond that based on instinct, habit, or impulse alone [2], facilitating successful adaptation to unpredictable environments, stressful situations, and challenging tasks. People with poor executive functions commonly have difficulty interacting with others both in terms of general social competence and the ability to inhibit socially inappropriate behaviors. A mature executive system enables people to a) inhibit socially impulsive behavior, b) guide behavior in social contexts by applying learned rules of appropriateness, c) consider other people's perspectives and interests when making decisions, and d) foregoing immediate gratification in the interest of long-term gain. In many respects, the executive system differentiates adult social behavior from that of normally developing young children [2]. Common terms to describe persons with executive impairments that may also characterize the very young or immature child include being concrete, egocentric, socially inappropriate, disorganized, childlike, impulsive, inflexible, and impatient [2]. Executive function impairments are considered among the most disabling of all cognitive impairments following TBI because they pervade virtually all aspects of a person's ability to function in his or her personal or professional life [3]. They are inherently tied to academic, vocational, and social success, roles associated with independence and life satisfaction. Impaired executive functions are sometimes referred to as executive dysfunction or dysexecutive syndrome.

\section{Understanding executive functions within the continuum of rehabilitation following TBI}

Executive functions are thought to be heavily influenced by the frontal lobes and subcortical limbic system, which govern most cognitive functions, especially those involving new and unstructured situations. Commonly accepted components of executive functions are listed and defined in table 1.While definitional problems exist, there is little disagreement regarding the impact of executive dysfunction on emotional, behavioral, and social outcomes following TBI. During normal development, many executive functions do not fully develop until late adolescence and early adulthood and represent higher level adult thought, reasoning, and decision making. When damaged, an individual's behavior and social functioning appears more reflective of earlier stages of development. Examples include difficulty delaying gratification, inability to anticipate consequences, verbal and behavioral disinhibition, impaired awareness of and/or concern for social norms, apathy, and indifference. Adult family, social, and vocational roles are dependent upon higher level cognitive skills and, when compromised, have significant social, financial, and personal consequences. 
The stages and settings associated with recovery following TBI are summarized in figure 1 . The early stages of recovery following moderate to severe TBI generally involve a period of acute care and rehabilitation which are hospital based and include medications, surgery, and therapeutic exercises/activities directly targeted to managing identified symptoms. In the United States, there is a trend towards decreasing length of inpatient stay following TBI. According to a study by Turkstra [4], the average length of stay in inpatient TBI rehabilitation was 18 days. She noted that, compared to previous decades, patients with brain injury are "sicker when they are admitted to inpatient rehabilitation and sicker when they leave" (p. 333). Rehabilitation during the inpatient recovery period tends to be governed by the medical model, which emphasizes the patient's dependency on health care professionals who act in the interest of the patient in an effort to preserve and minimize the severity of impairments. While this approach is recognized as a necessary component of TBI treatment, it has been argued that by fostering the 'rehabilitation patient' role, the inpatient setting is poorly suited to address executive cognitive functions and facilitating the transition to important life roles.

\begin{tabular}{|c|c|}
\hline Term & Definition \\
\hline Self-awareness & $\begin{array}{l}\text { The ability to accurately recognize one's abilities and limitations. It is influenced by many factors } \\
\text { including memory, decreased sensory or perceptual abilities, impulsivity, and inability to plan for } \\
\text { the future. Deficits include displaying very limited or no apparent appreciation with regard to the } \\
\text { nature of difficulties or impairments and the impact of these on everyday functioning. They } \\
\text { impact ability to acceptance of feedback from others related to limitations, affecting the ability to } \\
\text { benefit from rehabilitation [5]. Impaired self-awareness impacts performance of social } \\
\text { interactions, including difficulties with personal boundaries, appreciating their impact on others, } \\
\text { managing arguments, anger management, and adjusting to unexpected changes [6]. }\end{array}$ \\
\hline Goal Setting & $\begin{array}{l}\text { The ability to determine what one wants and to foresee the future realization of those needs. } \\
\text { Goal attainment involves estimating task difficulty and self-evaluating performance so that } \\
\text { adjustments can be made, both of which are impacted by impaired self-awareness of deficits or } \\
\text { abilities. }\end{array}$ \\
\hline Initiation & $\begin{array}{l}\text { The ability to start an activity. Deficits in this area include lacking spontaneity, being slow to } \\
\text { respond, or lacking initiative. The individual may verbalize an intent to act but fail to follow } \\
\text { through [7]. Deficits may be misinterpreted as lack of motivation or drive and can be a } \\
\text { considerable source of frustration for both client and family. }\end{array}$ \\
\hline Inhibition & $\begin{array}{l}\text { Deficits include problems stopping - demonstrating disinhibition, impulsivity, and quick shifts in } \\
\text { behavior and emotional tone [7]. }\end{array}$ \\
\hline Planning & $\begin{array}{l}\text { The ability to organize the steps to complete an action, weigh alternatives, develop a framework } \\
\text { for carrying out the plan, prepare for setbacks in carrying out the plan, assemble the needed } \\
\text { materials and possess the skills necessary to carry out the plan [6]. Deficits impair the ability to } \\
\text { perform adult home, academic, or vocational roles. }\end{array}$ \\
\hline $\begin{array}{l}\text { Problem solving / } \\
\text { Decision making }\end{array}$ & $\begin{array}{l}\text { Requires integration of several cognitive skills, including attention, initiation, impulse control, } \\
\text { organization, categorization, mental flexibility, reasoning skills, and the ability to self-evaluate. } \\
\text { Deficits impact ability to select among various options to make a decision [8]. }\end{array}$ \\
\hline
\end{tabular}




\begin{tabular}{|c|c|}
\hline Mental flexibility & $\begin{array}{l}\text { The ability to initiate, stop, and switch actions depending upon feedback from the environment } \\
\text { during goal oriented task performance [8]. Deficits result in rigid, inflexible, or perseverative } \\
\text { behavior, seemingly becoming fixed to a behavioral set that is no longer productive or } \\
\text { appropriate [7]. Deficits result in behavior that appears perseverative and concrete with limited } \\
\text { ability to generalize current information for future problem solving. Tasks such as meal } \\
\text { preparation, driving, financial planning and many IADLs are affected. }\end{array}$ \\
\hline Attention & rontal lobe involvement results in distractibility and poor selective and divided attention. \\
\hline $\begin{array}{l}\text { Self-monitoring / } \\
\text { Self correction }\end{array}$ & $\begin{array}{l}\text { The ability to evaluate and regulate the quality and quantity of one's behavior to allow } \\
\text { identification and correction of incorrect responses. Deficits impact an individual's ability to } \\
\text { manage his or her own learning and apply correct strategies to accomplish goals. }\end{array}$ \\
\hline $\begin{array}{l}\text { Concept } \\
\text { formation / } \\
\text { abstraction }\end{array}$ & $\begin{array}{l}\text { The ability to make inferences from information. Deficits contribute to limited imagination, } \\
\text { problems generalizing from individual events, failing to plan ahead, and difficulty explain ideas } \\
\text { [8]. Information is viewed in a concrete manner, contributing to a rigid approach to thinking [10]. }\end{array}$ \\
\hline Categorization & $\begin{array}{l}\text { The ability to find commonalities among large amounts of information and assign objects and } \\
\text { events into groups [8]. Deficits impact all cognitive skills and abilities [11]. }\end{array}$ \\
\hline Generalization & $\begin{array}{l}\text { The ability to use a newly learned strategy in novel situations. Deficits impact ability to learn a skill } \\
\text { in one setting and apply it elsewhere. }\end{array}$ \\
\hline
\end{tabular}

Table 1. Categories of Executive Cognitive Functions [12].

Willer and Corrigan [13] argue that the longer the individual is hospitalized, the longer it can take to return to pre-injury roles. In this respect, decreasing length of inpatient stay could have potential benefits in the treatment of executive dysfunction if community based models were to receive the financial and professional support required to meet the needs of survivors and caregivers. Such a belief is supported by the extensive accounts of poor adjustment to the community following TBI, leading to discussions about TBI rehabilitation models that may better suited to the goal of community re-integration. In this respect, decreasing length of inpatient could have potential benefits in the treatment of executive dysfunction if community based models are adequately were to receive the financial and professional support required to meet the needs of survivors and caregivers. However, the development, implementation, and support for such models must be considered to be early in terms of their contributions to the TBI continuum of recovery. Gordon and colleagues [14] summarized these historic service delivery problems, along with the need to extend services beyond the medical model of symptom management, as follows:

... although individuals with TBI have been described as being sometimes "unaware," this term can just as easily be applied to rehabilitation service providers, insurance companies, and government officials in years past in describing their understanding of the impairments and service needs of individuals with TBI (p.321).

Unfortunately, this sentiment continues to be expressed today as community services remain inaccessible for many who could benefit from them [4]. Willer and Corrigan [13] postulated that the challenging transition to the community following TBI is best achieved through 
recognizing individual differences and implementing client centered interventions that involve the individual and the environments within which they participate. Since the time the model was first described, it has garnered considerable support and has served as a foundation for various assessment and treatment approaches designed to facilitate community re-entry. Their Whatever it Takes approach is based upon the following principles:

1. No two individuals with acquired brain injury are alike;

2. Skills are more likely to generalize when taught in the environment where they can be used;

3. Environments are easier to change than people;

4. Community integration should be holistic;

5. Life is a place-and-train venture;

6. Natural supports last longer than professionals;

7. Interventions must not do more harm than good;

8. The service system presents many barriers to community integration;

9. Respect for the individual is paramount; and

10. Needs of individuals last a lifetime; so should their resources.

The model has supported the emergence of community based rehabilitation approaches, including various coaching models such life skills training and supported employment, both of which have demonstrated positive rehabilitation outcomes. Through its emphasis on natural environments and holistic recovery, it is also well suited to the assessment and treatment of executive functions.

The progression from acute care to community is generally marked by a reduction in environmental structure. Institutional based rehabilitation tends to be marked by pre-established schedules - wake-up times, meal times, therapy times, and visiting times. In addition, patients tend to be taken to therapy sessions, appointments, meals and activities by staff and rarely participate in menus or the nature of service providers. In such settings, the reduced need for independent goal setting, decision making, and problem-solving limit opportunities to utilize higher level cognitive functions. Consequently, the extent of executive dysfunction tends to manifest later in the rehabilitation continuum, often challenging family members and providers to address previously undetected deficits and behaviors.

\section{Executive functions as barriers to participation}

The International Classification of Functioning Disability and Health (ICF) (Figure 2) represents an important contribution to the process of understanding and documenting the structural, functional, personal, and social manifestations associated with disability. The 


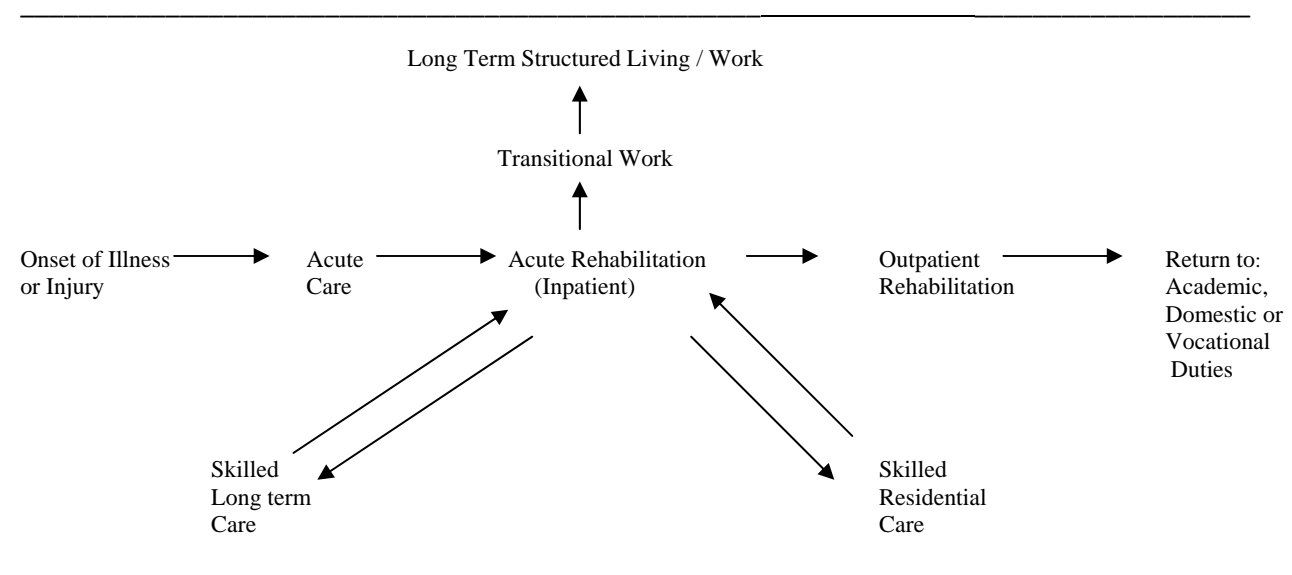

From "Living with Brain Injury: A Guide for Families (2 ${ }^{\text {nd }}$ Edition)" [15]. Copyright 2001 by Healthsouth Press. Reprinted with permission of the author.

Figure 1. Traumatic Brain Injury Recovery Tree

model is also well suited to conceptualizing the impact of impaired executive functions following TBI and facilitating more effective methods of evaluation and intervention. In the ICF, the construct body structures and functions (impairments) addresses the functional and structural integrity of the body systems while considering duration of condition and developmental stage of the individual [16]. Activities represent the performance of the person acting within the context of their culture. These two areas are emphasized in the earlier stages of the TBI rehabilitation continuum. The ICF defines an individual's participation as:

... the nature and extent of a person's involvement in life situations in relation to Impairment, Activities, Health Conditions and Contextual Factors. Participation may be restricted in nature, duration, and quality, e.g. participation in community activities, obtaining a driver's license ... [17].

As opposed to activities (based upon the ICF), which occur at the level of the individual, participation occurs at the societal level and is assessed by comparing participation in life activity of persons with and without disability within the context of society [18]. As is commonly reported following TBI, a participation reduction involves the social, familial, educational, vocational, or other role disadvantage associated with a disability such as failure in school or loss of a job due to a communication deficit [19]. The ICF serves as a useful guide for research, assessment and intervention of executive cognitive functions, placing the ultimate rehabilitation focus on community participation over impairment remediation. It has also influenced the rapid development of measures looking beyond impairments and activity limitations to include evaluation of the environments by which individuals participate in meaningful roles. 


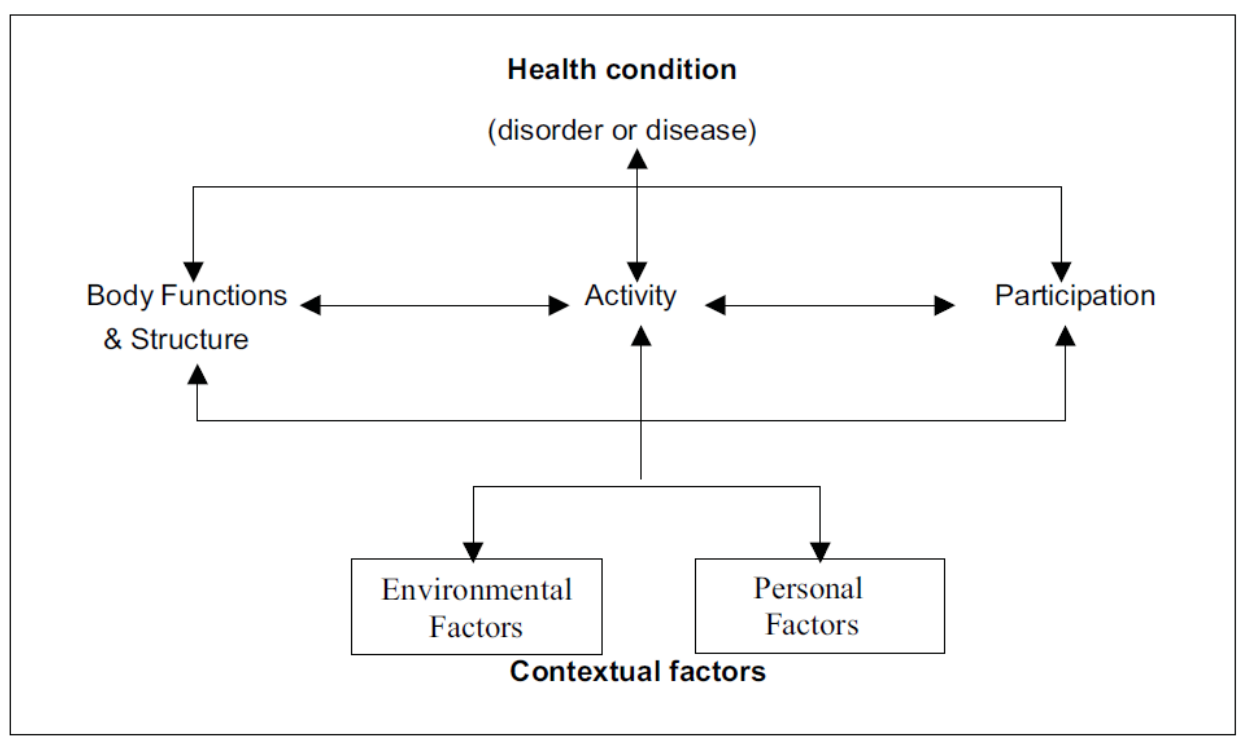

Figure 2. The International Classification of Functioning, Disability, and Health [16]. Copyright 2001 by the World Health Organization. Reprinted with permission of the author.

Executive dysfunction represents a participation level condition involving difficulties performing tasks within the context in which the person lives [16]. Participation focused assessment requires a top-down approach, starting with gathering information on what the individual wants to do, followed by an analysis of the person as he or she performs the desired tasks. In contrast to assessment within the medical model, consideration of the causes of the problem, including client factors is the final stage of the top-down evaluation process [20]. Contextual factors within the environment that contribute to societal participation including features of the physical, social, and attitudinal world together with the attributes of the individual [16]. Evaluation of such factors and considering them within the treatment plan is consistent with the Whatever it Takes approach and advocated by many experts in the field of TBI rehabilitation $[4,21]$.

Given the contributions of executive cognitive functions to social competence and adult social participation, it is no surprise that social isolation is among the most reported and profound life changes for persons with TBI. According to Rowlands [22], with the passage of time, the depth of social relationships tends to decrease, taking on a transient quality and contributing to the common complaint of loneliness. Studies looking at marital relationships following TBI have highlighted the coping challenges that spouses face dealing with behaviors such as emotional unpredictability, self-centeredness, and 'child-like' behaviors. Poor communication skills following TBI results in reduced participation in social activities and decreased life satisfaction [23]. Research has also suggested that, two years 
post-injury, persons with TBI still experience difficulties with social skills, which often lead to social isolation and depression [24].

Attention, memory, learning, and social-emotional impairments coupled with executive function and self-regulation impairments place individuals with TBI at unique risk for failure when attempting to return to work or school [25]. Individuals with TBI often experience difficulty securing and/or returning to competitive employment post-injury and maintaining employment for extended periods of time. Estimates of the employment rate for person with TBI range from $20 \%$ to $50 \%$ depending on the severity of injury, the prior work experience of the individual, and demographic characteristics (e.g. age, education, and socioeconomic status). The National Longitudinal Transition Study-2 reported that students with TBI whose injuries occurred before the onset of postsecondary education demonstrated significantly lower college graduation rates than their non-disabled peers [26]. If residual cognitive and social impairments remain unidentified by the academic institution, the student may not be offered needed accommodations and supports. These students are at greater risk for frustration, failure, social rejection, and placement in special education settings with students with dissimilar learning and social issues [27]. Students injured late in high school frequently struggle with more problems in college, where the levels of special services and TBI awareness are often even lower [28].

\section{A comprehensive model for approaching evaluation and treatment of executive functioning deficits}

Executive functions pose both assessment and intervention challenges for the rehabilitation professional. The manifestation of executive dysfunction is frequently context dependent and dynamic, rendering narrow band, static, office based assessment tools poorly suited to accurate measurement of the impact of impairments on community participation [21]. Compounding the issue is the need for rehabilitation professionals, particularly in inpatient settings, to quantify progress to third party payers, contributing to the use of didactic worksheets and activities that reduces the intervention process to a series of checklists of cognitive benchmarks [4]. As discussed previously, executive cognitive functions are more heavily relied upon during unstructured daily social, vocational / educational, and community activities. As such, many have argued for a more real-world approach to evaluation involving observations in the context of everyday activities, away from the acute care and structured hospital environments. To facilitate this means of evaluation, Burgess and colleagues [29] outline the following characteristics of everyday activities:

1. Many tasks

2. Interleaving - Performance on these tasks needs to be dovetailed in order to be time effective.

3. One task at a time - Due to cognitive or physical constraints, only one task can be performed at a time. 
4. Interruptions and unexpected outcomes - Unexpected, sometimes high priority, interruptions occur, and things will not always go as planned.

5. Delayed intentions - The time to return to a task that is already in progress is not signaled directly by the situation.

6. Differing task characteristics - Tasks usually differ in terms of priority, difficulty, and the length of time they will occupy.

7. Self-determined targets - People decide for themselves what constitutes adequate performance.

8. No immediate feedback - No minute to minute performance feedback. Failures are not signaled at the time they occur.

Figure 3 illustrates a proposed hierarchical model for the treatment of executive functions. Its organizational structure is influenced by the belief that rehabilitation of executive dysfunction begins with an appreciation, understanding, or awareness of deficits by the individual with TBI along with a perceived need for personal change [30]. During recovery from TBI, the convergence of emotional states and memory of abstract mental states facilitate the emergence of awareness. Decreased awareness of one's cognitive, behavioral, physical and emotional impairments is commonly cited after TBI and recognized by researchers and clinicians as one of the greatest obstacles in brain injury rehabilitation [31-32]. Not only does it affect the individual's belief about their impairments, but their belief in their ability to benefit from rehabilitation. Individual's post-TBI who show an accurate perception of themselves, as well as a greater willingness to change, demonstrate a better transition home and to the community than those who inaccurately perceive their limitations [33].

Within the model, rehabilitation to facilitate self-awareness begins with therapeutic relationship building, goal setting, and participation in activities meaningful to the client. Decreased self-awareness should not be viewed as all or none. Various models support the notion of some form of hierarchy or degree of severity that can vary depending on the area of function being assessed and the approaches used to make the assessment [32]. Three levels of awareness have been described - intellectual, emergent, and anticipatory - progressing from having an understanding of the limitations to being able to anticipate that a problem is likely to happen because of some deficit. [33] Through the process of participating in individual, group, and community activities, with formal and informal feedback provided regarding performance, treatment goals are revised to reflect emerging self-awareness. The process continues with instruction in other aspects of executive dysfunction implemented on an ongoing basis. Failures and consequences foster awareness of deficits. Successes build the self-esteem and self-confidence needed to take risks and persevere in the face of challenge. As is the case with all forms and learning, both successes and failures are normal aspects of development and, in the case of TBI rehabilitation, essential to the recovery process. Such a formula may seem simple, but it is not. The following sections expand upon this process, highlighting the challenges facing rehabilitation providers and the effort and commitment required by all members of the treatment team. 


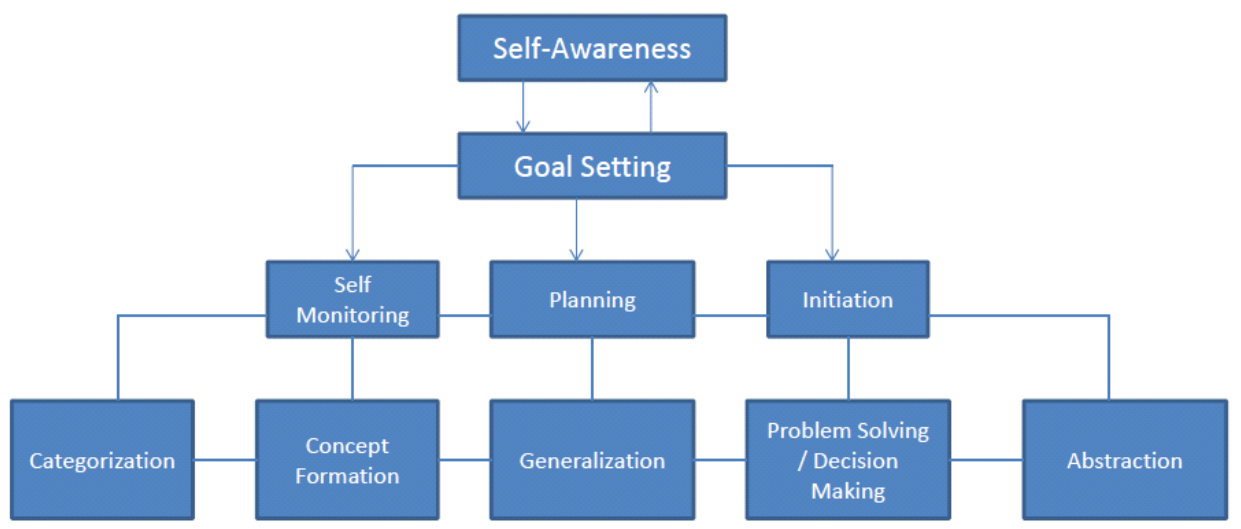

Figure 3. Proposed Model of Rehabilitation for Executive Dysfunction following TBI

\subsection{Exploring the relationship between self-awareness, goal setting, and life satisfaction}

Goal setting, as it pertains to executive dysfunction following TBI, can be considered both a stage in the rehabilitation process and a specific deficit area associated with impaired executive functions. The two are inter-related in "client centered" goal setting whereby treatment priorities reflect those areas deemed important to the client. Individualized treatment planning, as emphasized by Willer and Corrigan [13], involves active participation by the client in the establishing of treatment goals and priorities. Individuals lacking accurate awareness of deficits, as is common following moderate to severe TBI, are unable to effectively engage in this process, impacting goal identification, motivation, compliance, and outcomes. Trudel, Tryon, and Purdum [34] found a direct relationship between unawareness of impairments and poorer recovery seven years post-injury while Koskinen [35] reported that impaired awareness of deficits was strongly correlated with a decrease in family well-being ten years after TBI.

When impaired self-awareness impedes motivation and interest in rehabilitation, gaining insight into problem areas become a necessary element of recovery. It is generally recognized that life experiences following TBI that are relevant to a person's goals may increase that individual's understanding of injury related deficits and, subsequently, contribute to more realistic expectations about future outcomes. According to Toglia and Kirk [36], self-awareness increases through participation in different types of tasks. During normal development, the frontal lobes and other cortical areas become "wired" by ones learning history. Damage to this cortical area necessitates a need for "re-wiring," a process that occurs through the consistent application of positive and negative consequences. However, adults post TBI are generally ill prepared for needed feedback when lacking awareness of deficits and after being accustomed to pre-injury independence. As such, they are likely to reject feedback from family and to resent authority. Central to the success of rehabilitation of executive cognitive functions is the establishing of a supportive, therapeutic relationship whereby the client has an understanding that they can fail at a task or make mistakes without losing the support of the rehabilitation 
therapist. Participation in tasks that can expose the severity of an individual's deficits and "restructuring of self-knowledge," [37] can represent a potential threat to self-esteem, personal control, and sense of independence, so coping strategies and emotional reactions must be monitored closely. Clients at this stage of rehabilitation may "test" a therapist's commitment to the therapeutic relationship by sabotaging tasks, or present with defiant, aggressive, or insulting behavior. If the therapist understands such actions and behaviors as a component of the relationship building process, then the client's behaviors can be interpreted as aspects of recovery as opposed to noncompliance or the need for a staffing change. Approaches to fostering the therapeutic relationship include negotiating to achieve a common understanding, validating the client's perspective, fostering self-advocacy, and providing encouragement and feedback [38]. The strength of the relationship is established over time through shared experiences and continued support. The process is rarely a smooth one, often characterized by a two steps forward, one step backwards progression involving challenges presented to the client, a response by the client, the provision of feedback, and another response. While thoughts and behaviors of persons with executive dysfunction may at times appear child and adolescentlike, it is critical that the use of a developmental template to understand such behaviors not result in infantilization. Interacting with clients in a disrespectful manner by professionals and family members runs opposite to the needed approach to facilitate positive change, including adult level interactions and social role modeling.

While a necessary element to addressing other elements of executive dysfunction, the emergence of self-awareness marks a vulnerable period of recovery, often characterized by frustration, anger, and emotional distress. It is at this time that the professional skill of the therapist can be a determining factor as to whether the recovery process continues or comes to a halt. In Wheeler's [39] study involving a group of 40 individuals with severe TBI enrolled in a community based residential rehabilitation program, a statistically significant decrease in overall self-reported life satisfaction was found at 90 day follow-up. This decrease occurred despite an increase in community integration as measured by improved independence in home management, social participation, and productive activity. It was hypothesized that participation in intensive individual and group activities, program participants became increasingly dissatisfied with life despite functional improvements that were deemed clinically significant but were well below pre-injury levels of functioning. The development of self-awareness postTBI is generally considered to be a gradual process that involves comparing performance on functional tasks in a familiar setting with one's pre-morbid functional level [40] and "coming to terms with their new selves" [30]. The early stages of increased self-awareness may involve an appreciation of physical deficits before cognitive, emotional, behavioral, or psychological difficulties. According to study by Trahan, Pepin, and Hopps [41], persons with TBI tend overestimate emotional, cognitive, and behavioral difficulties when compared to clinician ratings. Given the manner in which impaired awareness of deficits can impede treatment goal setting and implementation of specific interventions, efforts to facilitate engage the client in activities to increase self-awareness warrant considerable emphasis during community reentry following TBI. Unfortunately, this process tends to be complex, unpredictable, and affected by cognitive, emotional, and psychological factors. 
It is essential that the clinician appreciate the unique role of decreased life satisfaction to recovery and be prepared to work through this transition period using additional professional supports as needed. It would be easy to view decreased satisfaction as a negative and avoid putting the patient in challenging situations that contribute to frustration, sadness, and ultimately, improved awareness of deficits. However, significant life changes are often fueled by a desire to overcome a dissatisfying situation. In this respect, a patient who lacks awareness of deficits and is generally satisfied with life may pose a significant challenge for the rehabilitation therapist. How do we engage an individual in challenging treatment goals when they don't perceive a problem? The decision to make major life changes and the pursuit of challenging goals, such as career changes, relationship changes, or personal fitness programs are generally sparked by some element of dissatisfaction. In Wheeler's [39] study, the initial 90 day follow-up period characterized by dissatisfaction was followed by a non-significant increase in satisfaction at one year follow-up. Given the importance of life satisfaction as a rehabilitation outcome, it is difficult to consider a decrease in this area to be a positive progression in the treatment progress. However, if viewed as a temporary step in the recovery process, the rehabilitation provider is better suited to managing and supporting the client as well as educating others. Such a finding also helps the clinician educate family, other professionals, or payer sources who may become discouraged by the apparent emotional regression displayed by the client. Recognizing signs of emotional distress is a necessary aspect of this process.

Those with TBI and executive dysfunction are considered at risk for depression, suicidal ideation, and suicidal behavior during the recovery process. For many, the residual deficits associated with TBI are debilitating and persistent. Major depression is one of the most frequently reported behavioral sequelae after TBI. In a multi-center study involving 666 nonacute individuals with moderate to severe TBI, fatigue (29\%), distractibility (28\%), angerirritability $(28 \%)$, and rumination $(25 \%)$ were identified as the most common depressive symptoms [43]. Theories attempting to explain the nature of the relationship between TBI and depression include pre-injury depression, pre-injury personality type, social integration after injury, family support, neurochemical imbalances, and site of anatomical damage [37, 43-44]. Depression complicates the process of recovery and rehabilitation because it contributes to increased effort in information processing and by creating general apathy towards rehabilitation [43]. Additionally, unemployment, social isolation, and emotional distress, combined with reduced cognitive resources increases the susceptibility of persons with TBI to contemplate suicide and engage in suicidal behavior [45]. The majority of studies on this topic report on the presence of suicidal ideation, estimated to be approximately $18 \%-23 \%$ among persons with TBI $[45,46]$ compared to approximately $3 \%$ in the general population [47]. Simpson and Tate [49] identified four pre-injury risk factors for suicidal ideation for persons with TBI: suicide attempts, alcohol abuse, drug abuse, and emotional / psychiatric disturbance. Of these, only pre-injury alcohol and substance abuse was related to suicidal ideation in a separate study [49]. Identification of specific post-injury risk factors has proven to be illusive to researchers. Research suggests that there is no critical period post-injury during which suicidal ideation is more likely to occur [45] and is hence is considered equally likely at any time after injury. 
It is important to make a distinction between organic self-awareness deficits (i.e., anosognosia), a component of executive cognitive functions, and psychological denial, a psychological defense mechanism [36]. Both can be present and whether together or in isolation, complicate recovery. When the nature of a traumatic event exceeds one's capacity to cope, psychological denial represents an involuntary and useful coping strategy during the early stages of recovery. Denying that the event has occurred allows one to consciously maintain a sense of competence instead of overwhelming depression and anxiety. However, continued nonacceptance of the TBI beyond the acute stages of recovery is associated poorer life outcomes [50-51]. Individuals in denial of their disability have partial knowledge of their impairments and struggle to accept and deal with this new information [52]. Psychological interventions to decrease denial should be incorporated into post-acute rehabilitation.

\subsection{Individual and coaching approaches}

Optimal treatment for executive dysfunction following TBI involves a combination of individual and group interventions that afford participation in home, community, vocational / school, and leisure activities with ongoing feedback provided in regards to performance. Oneto-one approaches are well suited to specific functional IADL skills training but have limitations, especially in regards to elements of social behavior. Many intervention models in occupational therapy and psychology involve the therapist "coaching" the client with TBI in both clinic and community settings. Sloan and colleagues [38] described skills development following TBI within a Community Approach to Participation (CAP). The authors detail the use of the approach within an occupational therapy treatment program, emphasizing the following components:

- Skills being addressed are related to the individual's goals: The top-down approach is based on the notion that clients are more motivated when there is an explicit link between the skill and the desired goal.

- Simplify and structure the task in which the skills are to be learned: Tasks should be simplified to increase the likelihood of success. Strategies may be utilized to compensate for impairments. Self-confidence and skill level increase and the individual becomes better able to meet everyday challenges.

- Build on strengths: Observing the client allows the therapist to identify personal strengths and skills that can serve as a positive platform for skill development. Pursuing pre-injury activities may facilitate success, based on the notion that it is easier to relearn an old skill than learn a new one.

- Develop routines: The goal of skill development is automatic performance within the context of the client's daily routine. Routines provide opportunities for repeated, consistent practice and contexts provide natural cues and prompts.

Wheeler [39] described a life skills training program that, when combined with daily group treatment, resulted in significant improvements in areas related to social integration and productive activity. The intensive life skills training utilized a one-on-one Life Skills Trainer (LST) to maximize the client's level of personal accountability, to provide immediate and 
consistent feedback regarding the social appropriateness of the client's behavior, and to provide ongoing training in the use of compensatory cognitive strategies. The LST provided continual intervention to facilitate and enhance the client's independent living skills via verbal cuing, training in compensatory skills, structuring of daily activities, redirection, assistance with problem-solving, encouragement of targeted behaviors, and cuing for safety awareness. The role of the LST or "Life Coach" is based on the psychotherapeutic relationship; i.e., it is the therapeutic bond between the LST and the client that provides the reinforcement for even the smallest of gains and the anticipated loss of this relationship that serves as a disincentive to unwanted behaviors. It is the essential collaboration or partnership between the client and the LST that provides the client with the confidence (i.e., sense of self-efficacy) to strive to conquer the brain injury and its associated deficits. In the context of this therapeutic relationship, the LST provides immediate, direct contingencies for behavior in a natural environment. The one-on-one nature of the relationship permits the LST to remain "in tune" with the client at all times, thereby maintaining the very delicate balance between praise and extinction/ punishment that is need to provide encouragement while at the same time increasing awareness of deficits.

The curative role of the relationship between the client and the LST is rooted in the principles of social learning. This theory maintains that behaviors are strengthened/increased or weakened/decreased as a function of events which follow them. Positive reinforcers increase the frequency of the behavior they follow. There are two types: a) Primary or unconditioned reinforcers do not require special training to acquire reinforcing value (e.g., food, water); b) Secondary or conditioned: reinforcers acquire reinforcing value through learning (e.g., praise, grades); that is, neutral stimuli acquire reinforcing when repeatedly paired with events that are reinforcing. Social reinforcers, such as verbal praise, attention, physical contact, and facial expression, are conditioned reinforcers. For social reinforcers to have reinforcing value, they must be paired with a variety of positive experiences. Thus, in order for the relationship with the LST to matter to the client (i.e., to take on reinforcing value), the LST must first take the time to engage in mutually enjoyable experiences with the client - spend meaningful time listening to the client, engaging in the client's preferred activities. Through this process, the client and the LST form a therapeutic bond or alliance. Once formed, this relationship may then be utilized - through the application of traditional behavioral techniques such as extinction, shaping, fading, differential reinforcement of other behavior (DRO) - the reinforcing value of this relationship can be utilized to increase the frequency of wanted behaviors and decrease the frequency of unwanted behaviors.

The involvement of a one-on-one LST on a 24 hour per day basis in the home and in the community can provide the opportunity for continual intervention to address common neurobehavioral problems via verbal cuing and training in compensatory skills. For example, many individuals with brain injuries exhibits verbal disinhibition resulting in inappropriately sexual, hostile, or irrelevant speech. To address this behavior, the LST establishes a nonverbal cue (e.g., tug of the ear) that signals the client to monitor their speech and engage in a predetermined self-talk strategy such as "Is it my business? Does it pertain to topic? Is it sexual? Will it make people think more or less of me?" This type of self-cuing is very effective when cuing 
is provided immediately and consistently in a variety of situations. Similarly, the presence of the LST provides effective intervention for explosive outbursts. In this situation, the LST provides ongoing cuing in the home and community to assist the client in identifying the initial signs of sympathetic nervous system arousal (e.g., motor tension, accelerated heart rate). The client is then cued to remove themselves from the situation and initiate relaxation techniques such as controlled breathing, visual imagery, attention-diversion, or muscle relaxation. In-vivo rehearsal of these techniques enhances the client's ability to rapidly identify when they are becoming overwhelmed and agitated, thereby enabling the client to remove themselves from stressful situation before explosive behavior occurs.

Client centered goal setting has been presented in this chapter as a challenging but necessary component of TBI rehabilitation for executive dysfunction. Goal based measures, such as the Canadian Occupational Performance Measure (COPM) [53] have been used effectively to facilitate a sense of goal ownership with clients and measure client progress over time. Studies using these techniques report that individuals, including those with TBI, who generated their own goals, are more likely to want to work on the goals and report that the goals were important to them [54]. The COPM is a semi-structured interview whereby clients identify problem areas then rate their current level of performance and satisfaction with each area on a scale of 1 to 10. On re-assessment, respondents review their goals and again rate their performance and satisfaction on the goals identified in the initial assessment [55]. Studies using the COPM in a variety of brain injury rehabilitation settings have found it to be sensitive to change and that its use provides a sense of satisfaction with progress by both clients with TBI and their significant others [56]. It is important to note that client-centered goal setting is not synonymous with relinquishing total decision making to the client or doing whatever treatment the client believes is worthwhile [57]. Therapists have the responsibility to determine situations that place clients at risk, are fiscally irresponsible, or which have ethical or legal implications and to assist clients in examining and understanding such issues.

Ylvisaker and Feeney [2] utilized a similar approach that they termed a goal-plan-do-review routine. The approach involves the following steps:

1. Goal - What do I want to accomplish?

2. Plan - How am I going to accomplish my goal?

3. Identification of materials / equipment and steps / assignments necessary to act on plan.

4. Prediction - How well will I do? How much will I get done?

5. Do

6. Identification of problems that arise.

7. Formulation of solutions to identified problems.

8. Review - How did I do?

9. Self rating / Other rating (teacher, therapist, peer, family member)

10. What worked? What didn't work? 
11. What will I try differently the next time?

The authors note that executive system habits are more likely to become internalized when activities begin with the formulation of a goal and a plan, and end with a review that includes both a general rating of success and a listing of effective and ineffective strategies.

Goal attainment scaling (GAS) is another approach that has been effectively used to motivate participants, foster awareness of deficits, and provide a structured means to gauge progress. Within Dahlberg et al's [23] social communication skills training program, goals were developed with input from participants and scaled into five steps with progress evaluated by the client themselves, the group leaders, and a significant other. An example of a cognitive social goal from this study is as follows:

GOAL: I will interrupt less often during a 10 minute conversation.

1. I will interrupt 3 or more times during a 10 minute conversation with one prompt.

2. I will interrupt less than 3 times during a 10 minute conversation.

3. I will interrupt less than 2 times during a 10 minute conversation.

4. I will interrupt only one time during a 10 minute conversation.

5. I will not interrupt during a 10 minute conversation.

Goals focused on numerous aspects of social communication including self-awareness (i.e., "I will be able to identify social skill strengths and weaknesses"), speech (i.e., I will speak clearly enough to be understood $90 \%$ of the time"), and interpersonal ("I will be able to name 2 places to meet new people, and will visit 1 of those places). GAS can be used alongside instruments like the COPM to translate the broad client-centered goals from the COPM into specific behavioral actions. In a study combining use of the COPM and GAS with both individuals with TBI and caregivers, Doig and colleagues [54] concluded that the measures were sensitive to change for persons with TBI. They noted however that, in some clients with moderate to severe awareness deficits, client ratings on the COPM did not reflect positive change even though objective assessment and significant other ratings indicated otherwise. By receiving feedback about performance during the therapy and GAS process, the clients' self-awareness improved over time and post-intervention COPM ratings became more realistic.

Turner and colleagues [1] developed a framework for classifying self-identified goals following TBI that can be utilized during rehabilitation to monitor the scope of an individual's treatment plan. The categories, focusing on common community reintegration problems following TBI, are as follows:

1. Relationships (e.g., family, interpersonal relationships, friendships, and social activities);

2. Work and education (i.e., returning to previous employment or school, seeking new employment, considering new educational pursuits or training, and volunteer activities);

3. Injury rehabilitation;

4. Health and leisure; 


\section{Daily life management; and}

6. General life / personal goals.

When engaged in goal setting, clients with TBI at both post-acute and long term phases of recovery tended to focus more on "injury" goals consistent with the physical aspects of recovery. This heightened focus on physical deficits over cognitive, social, and emotional difficulties, was more pronounced in the post-acute group and consistent with research on self-awareness deficit and TBI. Continued life experiences relevant to an individual's goals may increase one's understanding of the implications of the injury, leading to more realistic expectations about future outcomes and subsequently, expansion in the variety of identified goal areas. Goverover and colleagues utilized self-awareness training during instrumental activities of daily living (IADL) tasks [58]. The program involved having participants define the goals of the task, predict task performance, anticipate and preplan for any obstacles that they feel will encounter during task performance, choose a strategy to circumvent such difficulties, and anticipate the amount of assistance they feel they will need to successfully perform the task. Then, after performing the IADL task, participants completed a selfevaluation of the task, engaged in a discussion with the therapist regarding task performance and performance relative to pre-task questions, received feedback from the therapist regarding observed performance, and finally, wrote about the experience in a journal. While improvements were observed in specific task awareness, self-regulation, and functional performance, improvements were not observed in general awareness and community integration.

\subsection{Vocational / Educational rehabilitation}

Being employed is consistently associated with better quality of life in TBI survivors [59] and represents an important rehabilitation outcome. The capacity to work contributes to an individual's self-esteem and gives a person a sense of control over his or her life from the standpoint of economic independence, and structured, purposeful daily routine. Additionally, work affords social opportunities, the many benefits of which were discussed previously. Unemployed survivors with moderate to severe TBI have been found to be mildly clinically depressed, more fatigued, and experienced a variety of other symptoms compared to their employed counterparts, despite equivalent levels of cognitive functioning or pre-injury job satisfaction [60]. Individuals with executive dysfunction generally experience considerable difficulty securing and/or returning to competitive employment post-injury. Those that do find a job tend to have difficulty maintaining it for extended periods of time. Estimates of employment rates for persons with TBI range from $20 \%$ to $50 \%$, depending on factors such as injury severity, prior work experience, and demographic characteristics including age, education, and socioeconomic status [61]. Positive factors influencing one's capacity to return to work after brain injury include a younger age, a higher level of education, better post-injury cognitive abilities, and the absence of a psychiatric disorder or problem with substance abuse. Inconsistent links have been found between injury severity and return to work, but generally speaking, more severe injuries have a more negative impact on return to work, in part because of greater cognitive impairment. 
Principles of skills coaching are central to many return to work programs and models of supported employment [62], school re-entry [25], social integration, and general home and community functioning [38-39]. Achieving independence in basic self-care and some advanced living skills sets the ideal foundation for community participation and more challenging cognitive tasks. Essential to this is self-awareness of capacities and limitations and acceptance of one's disabilities. As with other aspects of community integration, poor self-awareness has been suggested to be a major barrier to the successful return to productive activity [63]. In such cases, productive volunteer activity may be utilized to promote self-awareness, acceptance, and psychological well-being as well as promote social roles during the recovery process. Volunteer work allows persons with brain injury to test their limits and abilities, to explore new avenues of work, to develop new interests, and to discover new sets of capacities that may lead to productive activity despite existing limitations [64]. Despite having a larger portion of more severely injured individuals on long-term disability, which one might associate with higher risk for psychological distress, a group of individuals with TBI engaged in volunteer activities was found to be comparable in their psychological adjustment to a group of TBI survivors who were competitively employed or engaged in academic pursuits [64].

Kennedy and Krause [25] presented a dynamic coaching model of supported education, involving self-regulated learning, with two college students with severe TBI. The intervention involved the following:

1. Guided conversations about strengths and weaknesses based on assessment test results;

2. Establishing academic and specific goals around themes of studying and learning, time management, and relating to others;

3. Discussion of skills related to studying and time management-useful approaches versus ineffective ones pertaining to each course;

4. Identification of human supports such as friends, family, disability service counselors, vocational rehabilitation counselors;

5. Identification of, and plan to use, academic accommodations;

6. Direct individualized coaching including direct instruction on agreed upon strategies and evaluation of the effectiveness of such strategies (i.e., what is working and what is not) related to assignment and test performance; and

7. End of semester portfolio preparation where students outline relative strengths and weaknesses, along with descriptions of various study and learning strategies and time management tools that were beneficial throughout the academic year.

These authors reported that the approach yielded positive results for both individuals as measured by improved performance on tests and assignments, good academic standing, completion of the majority of credits attempted, and positive academic decision making.

For people with TBI, one determinant of satisfaction with life in general is the resumption of leisure activities and, more specifically, involvement in activities outside the home and involvement with friends [65]. Studies show a disruption in leisure engagement after TBI, with 
changes in the frequency of socialization, time spent on leisure type activities, and the types of activities done compared to prior to the traumatic injury. Over time, the successes derived from leisure participation can help build self-esteem, recognized as an important attribute in the challenging process of community reintegration. Involvement in leisure activities helps to create a broader social network while providing respite or additional social opportunities for family and friends. Additionally, leisure represents an occupation through which therapeutic goals can be achieved [66], and self-awareness fostered, and an opportunity for physical and cognitive rehabilitation whereby the individual can find meaning and enjoyment in life while testing identity changes following TBI in a less threatening setting [67-68]. Leisure also fosters the development of skills to deal with environmental influences, increases social interaction, and enhances skills that can be transferred to other activities of daily living.

\subsection{Group approaches to facilitate social participation}

As discussed throughout this chapter, interventions to address social competence and social participation represent a critical element of any rehabilitation program addressing executive cognitive functions. The effect of impaired social skills manifest in virtually every discussion of important community based TBI outcomes - family, friendships, employment, school, and leisure [69-70]. For example, while most adult survivors remember how to do their pre-injury job and, at some point, may be able to return to work, their success tends to be temporary because of interpersonal difficulties, especially in the presence of deficits in executive cognitive functioning [71]. Social skills include both basic competencies and situational relevant behaviors that enable a person to be accepted and liked in chosen social settings [69,72]. Socially skilled people are capable of influencing others in a positive manner and with the effect that they intended. They are also able to be affected positively by others in the way that others would like to affect them. Ylvisaker and Feeney [2] conceptualized the qualities of socially skilled people as including the following:

1. Cognition - social cognition (i.e., knowledge of relevant social rules, roles, and routines and ability to effectively perceive and interpret the social behavior of others), general cognition, and decision making;

2. Communication (i.e., language and non-language behavior) - Communicating intentions effectively and in ways that are considered situationally appropriate by others; knowing how to enter into an interaction with others, comfortably maintaining that interaction, and negotiating conflicts;

3. Self - Awareness of interactive strengths and weaknesses, being reasonably comfortable with self as a social agent; and

4. Person support for interaction - Dressing and grooming self in ways considered appropriate in their social milieu, and understood and accepted by members of the social groups with which they choose to affiliate.

Similarly, Hawley and Newman [73] described social skills as including communicating needs and thoughts, listening and understanding others, giving and interpreting non-verbal 
communication, regulating emotions during social interactions, assertiveness, working with others to solve problems, and following social boundaries and rules.

Clients with TBI who demonstrate communication impairments and / or who experience social isolation and limited participation in their communities may benefit from group intervention [74]. As a social microcosm, therapy groups provide an ideal setting for interpersonal learning, social skill development, and interpersonal relationships that can exert a powerful influence on the individual [75]. Group interventions provide important social feedback from other group members, both positive and negative, allowing the client to address problematic social behaviors within the supportive structure of the group. While group topics can provide opportunities information to enhance social skills, it is through group dynamics and the "therapeutic community" that behavior changes occur. Therapist group leaders need to ensure that group structure be flexible enough to allow relationship building among participants so that the group serves to reinforce desirable social behavior and extinguish undesirable behaviors.

In their functional group model, Schwartzberg, Howe, and Barnes [76] present a task oriented approach that encourages active participation among members to achieve common group goals. Basic assumptions of the model include:

1. The goal of the functional group is not the product of the group, even though the group may have a meaningful product, but rather the learning process that occurs through active participation.

2. Functional groups nurture interpersonal and intrapersonal development through activity choice, climate, and goals.

3. Functional groups make use of both the human and nonhuman environment and object relations. Attention is directed to attachments to people and objects, separations from people and objects, and the symbolic nature of attachment.

4. Functional group leaders are cognizant of the individual's need for self-motivation and desire for mastery and guide the activity of the group accordingly.

Therapy group models are well suited to addressing many aspects of executive dysfunction can be integrated into various community based TBI treatment settings. Simmons and Griswold (2010) implemented a group intervention as part of a community based day program in an effort to empower members and improve their performance in daily life roles. The program involved both casual interactions and skill training groups pertaining to areas such as computer use, social skills, current events, or movie discussions. Structured group sessions focused on areas that were a) creative, b) emotional / spiritual, c) functional, d) vocational, e) recreational / leisure, and f) related to physical fitness. The researchers reported significant improvements over an eight week period. Similarly, Dahlberg et al. [23] conducted a twelve week social communication skills group (1.5 hour weekly sessions) that significantly improved both communication skills and self-reported life satisfaction. The topics of the group sessions followed the program described in Social 
Skills and Traumatic Brain Injury [73]. The program addresses numerous components of executive cognitive functioning and is arranged as follows:

1. Group overview: Learning the skills of a good communicator;

2. Self-assessment and setting goals;

3. Presenting yourself successfully and starting conversations;

4. Developing conversation strategies and using feedback;

5. Being assertive and solving problems;

6. Practice in the community;

7. Developing self-confidence through positive self-talk;

8. Setting and respecting social boundaries;

9. Video-taping and problem solving;

10. Video review and feedback;

11. Conflict resolution; and

12. Closure and celebration.

The program uses a group co-leader, allowing two clinician perspectives and two role models. Emphasis was placed on facilitating self-awareness, progressing to individual goal setting that utilized goal attainment scaling. The group process was used to foster interaction among group members, creating an environment conducive to feedback, problem solving, social support, and awareness that one is not alone. Finally, the group involved the family and friends and included homework assignments to facilitate generalization of skills to home and community environments. At each session, participants were provided with time to discuss events from the previous week, time in the middle of the session for an unstructured break, and time towards the conclusion of each session to summarize the meeting and plan for the following week.

Wheeler [39] emphasized the importance of weekly goal setting as part of any group curriculum for persons with TBI. This program involves clients and group leaders gathering so that clients may set attainable goals (typically 5-10 specific objectives) for the following week and then subsequently receive positive or negative feedback - depending on their success at meeting their weekly goals - from the remainder of the group when progress toward goals is reviewed each week. The practice of setting and evaluating weekly goals within the group is based in the observation that, after the initial 6-9 months postinjury, an individual's rate of recovery tends to slow down and appear to plateau. Perceiving that their rehabilitation efforts are of no avail, clients are prone to give up at this point. Setting weekly attainable goals provides the individual with a brain injury with the very important feedback that they are continuing to recover - thereby increasing their selfefficacy, i.e., their belief in their ability to do what is necessary to cope with their brain 
injury. The weekly goal-setting session permits the client to have an active role in determining their own course, in that the client is working on their own personal goals, rather than goals established by a therapist. Furthermore, setting attainable goals each week allows for the client to be praised and reinforced for even very small gains, so that most of the feedback the client receives is positive. For example, in this goal-setting group, a client may set a goal such as "No more than three angry outbursts per day" and then receive praise and applause for meeting this goal. By contrast, it is hard to imagine that family members would praise an individual with a brain injury for having 21 angry outbursts in a week. Thus, the setting of weekly attainable goals ensures that the feedback that the client receives is predominantly positive, thereby increasing their self-confidence and their belief in their ability to overcome their brain injury

\section{The role of the family in the recovery process}

Optimal community participation for the individual with TBI cannot be achieved without consideration of the role of the family and family dynamics. Understanding the severity of an individual's executive cognitive impairment may only become evident once the individual with TBI has been discharged from the rehabilitation facility, leaving the family and caregivers to deal with the challenges of community re-entry. The emergence of executive functions at this stage can give the appearance that the individual's deficits are getting worse when, in fact, they are a product of the challenges imposed by the demands and expectations of a typical daily routine. Ongoing emotional distress within the family has been reported to be a contributing factor to the breakdown in marital relationships, reduced personal health, and decreased social contacts experienced by family members [77]. Family members also report increased financial strain, altered or reduced job responsibilities, and reduced free time due to requirements associated with caring for the individual with TBI [77-79].

Turkstra [4] proposes increasing the role of the family during cognitive rehabilitation at the inpatient stage as a means of facilitating a more favorable transition to home and community. The family based approach is summarized below based upon the following goals:

1. Establishing a therapeutic alliance with patients and families, so that they identify occupational and speech and language pathologists as an ongoing resource as needs arise post-discharge.

2. Help patients and families observe and understand the natural history of cognitive recovery after traumatic brain injury to help them interpret behaviors they are seeing each day and appreciate their family members progress.

3. Provide patients and families with some tools to help manage everyday consequences of the patient's cognitive impairments at home.

4. Minimize bad habits that can develop during the early days post-injury when patients have normal implicit learning of habits but impaired declarative memory and reasoning. 
5. Help patients and families be advocates for their own needs post-discharge and educated consumers of cognition- related resources.

The significant strain placed on family members caring for injured relatives is well documented in the literature, negatively impacting physical health and contributing to emotional distress and the likelihood of depression [80-82]. Unfortunately, many family members and friends report that they still manage all of the activities of daily living and instrumental activities of daily living of the individual with a TBI 10 years after the trauma and that they are exhausted by having to do so [83]. Research suggests that the effects of TBI within the family structure are reciprocal. The well-being of the person with TBI affects the well-being of the family, and as one would expect, the well-being of the family affects the well-being of the injured person [84]. Hence the family system is more than a recipient of stress and strain following TBI, it most likely influences outcome. As such, involvement of family and caregivers by the rehabilitation team throughout the recovery process is critical. That may involve assisting families and caregivers in their own coping so that they are in a psychological state appropriate to the challenges that community re-entry may present.

\section{Conclusions}

Despite a growing interest in executive cognitive functions and their effects on community participation and life satisfaction following TBI, precise definitions of executive functions continue to elude clinicians and researchers. Disorders of executive functions, as is commonly seen following moderate to severe TBI, tend to be context dependent and present unique challenges in terms of both assessment and rehabilitation. This chapter presented an overview and hierarchical approach to the rehabilitation of executive cognitive functions. Beginning with therapeutic relationship building, the clinician engages the client in a collaborative program of activity designed to facilitate self-awareness and meaningful goal setting. The process tests the commitment and professionalism of the interdisciplinary team and may contribute to struggle, frustration, and periods of dissatisfaction by both client and their support system. By gaining an appreciation of deficits, clients are better suited setting realistic goals and making the social, cognitive, behavioral, and physical adjustments necessary for participation in interventions to specifically geared to the performance of important adult roles.

\section{Acknowledgements}

The author would like to thank Dr. James Phifer and the staff of Radical Rehab Solutions, LLC for their expertise and helpful insights pertaining to the content of this chapter. I would also like to thank Breanna Hart, OTS for her work in reviewing and editing the chapter. 


\section{Author details}

Steven Wheeler

Division of Occupational Therapy, West Virginia University School of Medicine, West Virginia University Injury Control Research Center, Morgantown, West Virginia, USA

\section{References}

[1] Turner, B., Fleming, J., Cornwell, P., Haines, T., \& Ownsworth, T. (2009).Profiling early outcomes during the transition from hospital to home after brain injury. Brain Injury, 23, 51-60.

[2] Ylvisaker, M. \& Feeney, T. (1998). Collaborative Brain Injury Intervention: Positive Everyday Routines. San Diego, CA: Singular Publishing Group.

[3] Tsaousides, T., \& Gordon, W. (2009). Cognitive rehabilitation following traumatic brain injury: assessment and treatment. Mount Sinai Journal of Medicine, 76, 173-181.

[4] Turkstra, L. (2013). Inpatient cognitive rehabilitation: Is it time for a change? Journal of Head Trauma Rehabilitation, 28(4), 332-336.

[5] Fischer, S., Gauggel, S.,\&Trexler, L. (2004).Awareness of activity limitations and prediction of performance in patients with brain injuries and orthopedic disorders. Journal of the International Neuropsychological Society, 10, 190-199.

[6] McDonald, B., Flashman, L.,\& Saykin,A. (2000). Executive dysfunction following traumatic brain injury: Neural substrates and treatment strategies. Neurorehabilitation, $17,333-344$.

[7] Mateer, C. (1999). The rehabilitation of executive disorders. In Stuss, D., Winocur, G., \& Robertson, I. (Eds.), Cognitive NeuroRehabilitation (pp. 314-332). Cambridge, UK: Cambridge University Press.

[8] Parente, R.,\& Hermann, D. (2003).Retraining cognition: Techniques and applications (2 ${ }^{\text {nd }}$. edition). Austin, TX: Pro-Ed.

[9] Goverover, Y.,\& Hinjosa, J. (2002). Categorization and deductive reasoning: Predictors of instrumental activities of daily living performance in adults with brain injury. American Journal of Occupational Therapy, 53, 509-515.

[10] Golisz, K.,\& Toglia, J. (2003).Perception and cognition. In: E. Crepeau, E. Cohn, \& B. Schell (Eds.), Willard and Spackman's Occupational Therapy. Philadelphia, PA: Lippincott, Williams, and Wilkins. 
[11] Ashley, M. (2004).Evaluation of traumatic brain injury following acute rehabilitation. In M. Ashley (Ed.), Traumatic brain injury rehabilitative treatment and case management. Boca Raton, FL: CRC Press.

[12] Zoltan, B. (2007). Vision, perception, and cognition (4 ${ }^{\text {th }}$ Ed.).Thorofare, NJ: Slack Incorporated.

[13] Willer, B., \& Corrigan, J. (1994). A model for community based services: The Whatever It Takes Model. Brain Injury, 8, 647-659.

[14] Gordon, W., Hibbard, M., Brown, M., Flanagan, S., \& Korves, M. (1999). Community integration and quality of life of individuals with traumatic brain injury. In Rosenthal, M., Griffith, E., Kreutzer, J. \& Pentland, B. (Eds.) Rehabilitation of the Adult and Child with Traumatic Brain Injury (pp.312-325). Philadelphia, PA: FA Davis.

[15] Senelick, R., \& Dougherty, K. (2001).Living with brain injury: A guide for families. Birmingham, AL: Healthsouth Press.

[16] World Health Organization [WHO].(2001). International classification of functioning, disability, and health. Geneva: author.

[17] World Health Organization. (1999) International Classification of Functioning and Disability: ICIDH-2, Beta Draft Short Version. Geneva, Switzerland: WHO

[18] Gray, D. \& Hendershot, G. (2000). The ICIDH-2: Developments for a new era of outcomes research. Archives of Physical Medicine and Rehabilitation, 81, S10-S14.

[19] Ylvisaker, M., Hanks, R., \& Johnson-Greene, D. (2002). Perspectives on rehabilitation of individuals with cognitive impairment after brain injury: Rationale for reconsideration of theoretical paradigms. Journal of Head Trauma Rehabilitation, 17(3), 191-209.

[20] Simmons, C., \& Griswold, L. (2010).Using the evaluation of social interaction in a community-based program for persons with traumatic brain injury. Scandinavian Journal of Occupational Therapy, 17, 49-56.

[21] Gioia, G., Kenworthy, L., Isquith, P. (2010). Executive function in the real world: Brief lessons from Mark Ylvisaker. Journal of Head Trauma Rehabilitation, 25(6), 433-439.

[22] Rowlands, A. (2001). Ability or disability? Strength-based practice in the area of traumatic brain injury. Families in Society: The Journal of Contemporary Human Services,82, 273-286.

[23] Dahlberg, C., Cusick, C., Hawley, L., Newman, J., Morey, C., Harrison-Felix, C., \& Whiteneck, G. (2007). Treatment efficacy of social communication skills training after traumatic brain injury: A randomized treatment and deferred treatment controlled trial. Archives of Physical Medicine and Rehabilitation,88, 1561-1573. doi:10.1016/j.apmr. 2007.07.033.

[24] Engberg, A.,\& Teasdale, T. (2004). Psychosocial outcome following traumatic brain injury in adults: A long-term population based follow-up. Brain Injury, 18, 533-545. 
[25] Kennedy, M.,\& Krause, M. (2011). Self-regulated learning in a dynamic coaching model for supported college students with traumatic brain injury: two case reports. Journal of Head Trauma Rehabilitation, 26, 212-223.

[26] Wagner, M., Newman, L., Cameto, R., Garza, N., \& Levine, P. (2005). After high school: A first look at the postschool experiences of youth with disabilities. A report from the National Longitudinal Transition Study-2 (NLTS2). Menlo Park, CA: SRI International. Retrieved August 18, 2012 from http://www.nlts2.org/pdfs/afterhighschool_report.pdf

[27] Deaton, A. (1990). Behavior change strategies for children and adolescents with traumatic brain injury. In E.D. Bigler (Ed.), Traumatic brain injury (pp.231-249). Austin, TX: Pro-Ed.

[28] Kennedy, M., Krause, M., \& Turkstra, L. (2008). An electronic survey about college experiences after traumatic brain injury. NeuroRehabilitation, 23, 511-512.

[29] Burgess, P., Veitch. E., deLacy Costello, A., \& Shallice, T. (2000). The cognitive and neuroanatomical correlates of multitasking. Neuropsychologia, 38(6), 848-863.

[30] O'Callaghan, A., McAllister, L., \& Wilson, L. (2012). Insight vs readiness: Factors affecting engagement in therapy from the perspectives of adults with TBI and their significant others. Brain Injury, 12, 1-12. doi:10.3109/02699052.2012.698788

[31] Noe, E., Ferri, J., Caballero, M., Villodre, R., Sanchez., A., \&Chirivella, J. (2005). Selfawareness after acquired brain injury: Predictors and rehabilitation. Journal of Neurol$o g y, 252,168-175$.

[32] Sherer, M., Bergloff, P., Boake, C., High, W., \& Levin, E. (1998). The Awareness Questionnaire: Factor structure and internal consistency. Brain Injury, 12, 63-68.

[33] Flashman, L., \& McAllister, T. (2002).Lack of awareness and its impact in traumatic brain injury. NeuroRehabilitation, 17, 285-296.

[34] Barco, P., Crosson, B., Bolesta, M., Wets, D., \& Stout, R. (1991).Training awareness and compensation in postacute head injury rehabilitation. In J. Kreutzer \& P. Wehman (Eds.), Cognitive rehabilitation for persons with traumatic brain injury: A functional approach (pp. 129-146). Baltimore, MD: Paul H. Brookes Publishing Co.

[35] Trudel, T., Tryon, W.,\& Purdum, C. (1998).Awareness of disability and long-term outcome after traumatic brain injury. Rehabilitation Psychology, 43, 267-281.

[36] Koskinen, S. (1998). Quality of life 10 years after a very severe traumatic brain injury (TBI): The perspective of the injured and the closest relative. Brain Injury, 12, 631-648.

[37] Toglia, J., \& Kirk, U. (2000).Understanding awareness deficits following brain injury. Neurorehabilitation, 15, 57-70. 
[38] Ownsworth, T., \& Clare, L. (2006).The association between awareness deficits and rehabilitation outcome following acquired brain injury. Clinical Psychology Review, 26, 783-795. doi:10.1016/j.cpr.2006.05.003

[39] Sloan, S., Winkler, D., \& Callaway, L. (2004). Community integration following severe traumatic brain injury: Outcomes and best practice. Brain Impairment, 5, 12-29.

[40] Wheeler, S. (2012). The impact of intensive community based rehabilitation on community participation and life satisfaction following severe traumatic brain injury. In A. Agriwal (Ed.), Brain Injury: Functional Aspects, Rehabilitation, and Prevention (pp. 95-120). Rijeka, Croatia: Intech Publishers.

[41] Dirette, D., \& Plaisier, B. (2007). The development of self-awareness of deficits from 1 week to 1 year after traumatic brain injury: preliminary findings. Brain Injury, 21, $1131-1136$

[42] Trahan, E., Pepin, M., \&Hopps, S. (2006). Impaired awareness of deficits and treatment adherence among people with traumatic brain injury or spinal cord injury. Journal of Head Trauma Rehabilitation, 21, 226-235.

[43] Seel, R., Kreutzer, J., Rosenthal, M., Hammond, F., Corrigan, J., \& Black, K. (2003). Depression after traumatic brain injury: A NIDRR model systems multi-center investigation. Archives of Physical Medicine and Rehabilitation, 84, 177-184.

[44] Jean-Bay, E. (2000). The biobehavioral correlates of post-traumatic brain injury depression. Journal of Neuroscience Nursing, 32, 169-176.

[45] Rosenethal, M., Christensen, B., \& Ross, T. (1998).Depression following traumatic brain injury. Archives of Physical Medicine and Rehabilitation, 79, 90-103.

[46] Simpson, G. \& Tate, R. (2007).Suicidality in people surviving traumatic brain injury: Prevalence, risk factors and implications for clinical management. Brain Injury, 21, 1335-1351.

[47] Kishi, Y., Robinson, R., \& Kosier, J. (2001). Suicidal ideation among patients during the rehabilitation period after life threatening physical illness. Journal of Nervous and Mental Disorders, 189, 623-628.

[48] Kessler, R., Berglund, P., Borges, G., Nock, M.,\& Wang, P. (2005).Trends in suicidal ideation, plans, gestures, and attempts in the United States, 1990-1992 to 2001-2003.JAMA, 293, 2487-2495.

[49] Simpson, G. \& Tate, R. (2002).Suicidality after traumatic brain injury: Demographic, injury and clinical correlates. Psychology and Medicine, 32, 687-697.

[50] Tsaousides, T., Cantor, J., \& Gordon, W. (2011). Suicidal ideation following traumatic brain injury: Prevalence rates and correlates in adults living in the community. Journal of Head Trauma Rehabilitation, 26.265-275. 
[51] Curran, C., Ponsford, J., \& Crowe, S. (2000). Coping strategies and emotional outcome following traumatic brain injury: A comparison with orthopedic patients. Journal of Head Trauma Rehabilitation, 15, 1256-1274.

[52] Moore, A., \& Stambrook, M. (1995). Cognitive moderators of outcome following traumatic brain injury: a conceptual model and implications for rehabilitation. Brain Injury, 9, 109-130.

[53] Prigatano, G., \& Klonoff, P. (1998). A clinician's rating scale for evaluating impaired self-awareness and denial of disability after brain injury. Clinical Neuropsychology, 12, 56-67.

[54] Law, M., Baptiste, S., Carswell, A., McColl, M. A., Polatajko, H., \&Pollock, N. (2005).The Canadian Occupational Performance Measure (5 ${ }^{\text {the }}$.). Toronto, Canada: Canadian Association of Occupational Therapists

[55] Doig, E., Fleming, J., Kuipers, P., \& Cornwell, P. (2010).Clinical utility of the combined use of the Canadian Occupational Performance Measure and goal attainment scaling. American Journal of Occupational Therapy, 64, 904-914.

[56] Law, M., Baptiste, S., Carswell, A., McColl, M.A., Polatajko, H., \& Pollock, N. (1998). Canadian Occupational Performance Measure (2nd ed. Rev.) Ottawa, ON: CAOT Publications ACE.

[57] Doig, E., Fleming, J., Cornwell, P., \& Kuipers, P. (2009). Qualitative exploration of a client centered, goal directed approach to community-based occupational therapy for adults with traumatic brain injury. American Journal of Occupational Therapy, 63, 559-568.

[58] Law, M., \& Baptiste, S. (2002).Working in partnerships with our clients. In M. Law, C. Baum,\& S. Baptiste (Eds.).Occupation based practice: Fostering performance and participation. Thorofare, NJ: Slack Incorporated.

[59] Goverover, Y., Johnston, M., Toglia, J., \& Deluca, J. (2007). Treatment to improve selfawareness in persons with acquired brain injury. Brain Injury, 21, 913-923.

[60] Nalder, E., Fleming, J., Foster, M., Cornwell, P., Shields, C., \& Khan, A. (2012). Identifying factors associated with perceived success in the transition from hospital to home after brain injury. Journal of Head Trauma Rehabilitation, 27, 143-153.

[61] McCrimmon, S.,\&Oddy, M. (2006). Return to work following moderate to severe traumatic brain injury. Brain Injury, 20, 1037-1046.

[62] Keyser-Marcus, L., Bricout, J., Wehman, P., Campbell, L., Cifu, D., Englander, J., High, J., \& Zafonte, R. (2002). Acute predictors of return to employment after traumatic brain injury: A longitudinal follow-up. Archives of Physical Medicine and Rehabilitation, 83, 635-641.

[63] Wehman, P., Kregel, J., Keyser-Marcus, L., Sherron-Targett, P., Campbell, L., West, M., \& Cifu, D. (2003).Supported employment for persons with traumatic brain injury: 
A preliminary investigation of long term follow-up costs and program efficiency. Archives of Physical Medicine and Rehabilitation, 84, 192-196.

[64] Wehman, P., Targett, P., West, M.,\& Kregel, J. (2005). Productive work and employment for persons with traumatic brain injury: What have we learned after 20 years? Journal of Head Trauma Rehabilitation, 20, 115-127.

[65] Ouellet, M., Morin, C.,\& Lavoie, A. (2009).Volunteer work and psychological health following traumatic brain injury, Journal of Head Trauma Rehabilitation, 24, 262-271.

[66] Anke, A.,\& Fugl-Meyer, A. (2003). Life satisfaction several years after severe multiple trauma: A retrospective investigation. Clinical Rehabilitation, 17, 431-442.

[67] Blacker, D., Broadhurst, L., \& Teixeira, L. (2008). The role of occupational therapy in leisure adaptation with complex neurological disability: A discussion using two case study examples. Neurorehabilitation, 23, 313-319.

[68] Lyons, R. (1993). Meaningful activity and disability: Capitalizing upon the potential of outreach recreation networks in Canada. Canadian Journal of Rehabilitation, 6, 256-265.

[69] Malley, D., Cooper, J., \& Cope, J. (2008).Adapting leisure activity for adults with neuropsychological deficits following acquired brain injury. NeuroRehabilitation, 23, 329-334.

[70] Dahlberg, C., Hawley, L., Morey, C., Newman, J., Cusick, C., \& Harrison-Felix, C. (2006). Social communication skills in persons with post-acute traumatic brain injury: three perspectives. Brain Injury, 20, 425-435

[71] Doble, S. E., Bonnell, J. E., \& Magill-Evans, J. (1991). Evaluation of social skills: A survey of current practice. Canadian Journal of Occupational Therapy, 58, 241-249.

[72] Arlinghaus, K., Shoaib, A., \& Price, T. (2005).Neuropsychiatric assessment. In J.M. Silver, T.W. McAllister, \& S.C. Yudofsky (Eds.), Textbook of traumatic brain injury (pp. 59-78). Washington, DC: American Psychiatric Publishing.

[73] Feeney, T.,Ylvisiker, M., Rosen, B., \& Greene, P. (2001). Community supports for individuals with challenging behavior after brain injury: An analysis of the New York State Behavioral Resource Project. Journal of Head Trauma Rehabilitation, 16, 61-75

[74] Hawley, L., \& Newman, J. (2006).Social skills and traumatic brain injury: a workbook for group treatment. Denver, CO: authors.

[75] Golisz, K. (2009). Occupational therapy practice guidelines for traumatic brain injury. Bethesda, MD: American Occupational Therapy Association.

[76] Yalom, I. (1995). The theory and practice of group psychotherapy. New York, NY: Basic Books. 
[77] Schwartzberg, S., Howe, M.,\& Barnes, M.A. (2008).Groups: Applying the functional group model. Philadelphia, PA: F. A. Davis Company.

[78] Hall, K., Karzmark, P., Stevens, M., Englander, J., O’Hare, P. \& Wright, J. (1994). Family stressors in traumatic brain injury: A two year follow-up. Archives of Physical Medicine and Rehabilitation, 75(8), 876-884.

[79] Tyerman, A. \& Booth, J. (2001). Family interventions following traumatic brain injury: A service example. Neurorehabilitation, 16(1), 59-66.

[80] Perlesz, A., \& O'Loughlan, M. (1998). Changes in stress and burden in families seeking therapy following traumatic brain injury: a follow-up study. International Journal of Rehabilitation Research, 21(4), 339-54.

[81] Knight, R., Devereaux, R., \& Godfrey, H. (1998).Caring for a family member with traumatic brain injury.Brain Injury, 12, 467-481.

[82] Leathem, J., Heath, E., \& Woolley, C. (1996).Relatives' perceptions of role change, social support, and stress after traumatic brain injury. Brain Injury, 10, 27-38.

[83] Connolly, D., \& O’Dowd, T. (2001).The impact of different disabilities arising from head injury on the primary caregiver.British Journal of Occupational Therapy, 64, 41-46.

[84] Lefebvre, H., Cloutier, G., \& Levert, M. (2008).Perspectives of survivors of traumatic brain injury and their caregivers on long-term social integration. Brain Injury, 22, 535-543.

[85] Vangel, S., Rapport, L., \& Hanks, R. (2011).Effects of family and caregiver psychosocial functioning on outcomes in persons with traumatic brain injury. Journal of Head Trauma Rehabilitation, 26, 20-29. 